\title{
ON THE TOTAL VERTEX IRREGULARITY STRENGTHS OF QUADTREES AND BANANA TREES
}

\author{
NURDIN \\ Department of Mathematics, Faculty of Mathematics and Natural Sciences, \\ Hasanuddin University (UNHAS), Jln. Perintis Kemerdekaan Km.10 \\ Makassar 90245, Indonesia, nurdin1701@gmail.ac.id
}

\begin{abstract}
A vertex-irregular total $k$-labelling $\lambda: V(G) \cup E(G) \longrightarrow\{1,2, \ldots, k\}$ of a graph $G$ is a labelling of vertices and edges of $G$ in such a way that for any different vertices $x$ and $y$, their weights $w t(x)$ and $w t(y)$ are distinct. The weight $w t(x)$ of a vertex $x$ is the sum of the label of $x$ and the labels of all edges incident with $x$. The minimum $k$ for which a graph $G$ has a vertex-irregular total $k$-labelling is called the total vertex irregularity strength of $G$, denoted by $\operatorname{tvs}(G)$. In this paper, we determined the total vertex irregularity strengths of all quadtrees and all banana trees.

Key words: Banana tree, quadtree, total vertex irregularity strength.
\end{abstract}

\begin{abstract}
Abstrak. Pelabelan- $k$ total tidak teratur titik $\lambda: V(G) \cup E(G) \longrightarrow\{1,2, \cdots, k\}$ pada graf $G$ adalah suatu pelabelan titik-titik dan sisi-sisi dari $G$ sedemikian sehingga untuk sembarang titik $x$ dan $y$ yang berbeda, bobot kedua titik tersebut, $w t(x)$ dan $w t(y)$, berbeda. Bobot titik $x$, dinotasikan dengan $w t(x)$, adalah jumlah label $x$ dan label semua sisi yang terkait pada $x$. Bilangan terkecil $k$ sedemikian sehingga graf $G$ mempunyai suatu pelabelan- $k$ total tidak teratur titik disebut nilai total ketidakteraturan titik dari $G$, dinotasikan dengan $\operatorname{tvs}(G)$. Dalam paper ini, ditentukan nilai total ketidakteraturan titik dari quadtree dan banana tree.

Kata kunci: Banana tree, quadtree, nilai total ketidakteraturan titik.
\end{abstract}

\section{Introduction}

The notion of a total vertex irregularity strength was introduced by Bača et al. [1]. For a graph $G=(V, E)$ with vertex set $V$ and edge set $E$ we define a

2000 Mathematics Subject Classification: $05 \mathrm{C} 78$.

Received: 26-01-2012, revised: 02-02-2012, accepted: 23-03-2012. 
labelling $\lambda: V(G) \cup E(G) \rightarrow\{1,2,3, \ldots, k\}$ to be a total $k$-labelling. The weight of a vertex $x$ under a total $k$-labelling $\lambda$ is

$$
w t(x)=\lambda(x)+\sum_{x z \in E(G)} \lambda(x z) .
$$

A total $k$-labelling is called a vertex-irregular total $k$-labelling of $G$, if every two distinct vertices $x$ and $y$ satisfy $w t(x) \neq w t(y)$. The total vertex irregularity strength of $G, \operatorname{tvs}(G)$, is the minimum positive integer $k$ for which $G$ has a vertexirregular total $k$-labelling.

There are not many graphs of which their total vertex irregularity strengths are known. Bača et al. [1] have determined the total vertex irregularity strengths for some classes of graphs, namely cycles, stars, and prisms. Besides that, Wijaya et al. [3] have determined the total vertex irregularity strengths of a complete bipartite graphs.

Bača et al. [1] derived some lower and upper bounds of the total vertex irregularity strength of any tree $T$ with no vertices of degree 2 as described in Theorem A.

Theorem A. (M. Bača, S. Jendrol', M. Miller, J. Ryan, 2007) Let T be a tree with $m$ pendant vertices and no vertex of degree 2. Then,

$$
\lceil(t+1) / 2\rceil \leq \operatorname{tvs}(T) \leq m .
$$

Recently, Nurdin et al. [2] determined the total vertex irregularity strength for several types of trees containing vertices of degree 2 , namely a subdivision of a star and a subdivision of a particular caterpillar. That paper also derived the total irregularity strength for a complete $k$-ary tree.

In this paper, we determine the total vertex irregularity strengths of all quadtree and all banana tree.

\section{Main Results}

Before we proceed to our main result we define a pendant edge of a tree. A pendant edge of a tree is an edge incident with a pendant vertex.

Definition 1. A quadtree of $d \geq 2$ dimensions, $Q_{d}$, is a tree that has one vertex of degree four, $\sum_{i=1}^{d-1} 4^{i}$ vertices of degree five, and $4^{d}$ pendant vertices.

Quadtrees are used in the construction of some multidimensional databases (e.g., cartography, computer graphics, and image processing). Besides that, quadtrees 
are most often used to partition a two dimensional space by recursively subdividing it into four quadrants or regions. The regions may be square or rectangular, or may have arbitrary shapes. For example, we can see that the dimension of the quadtree in Figure 1. is 3.

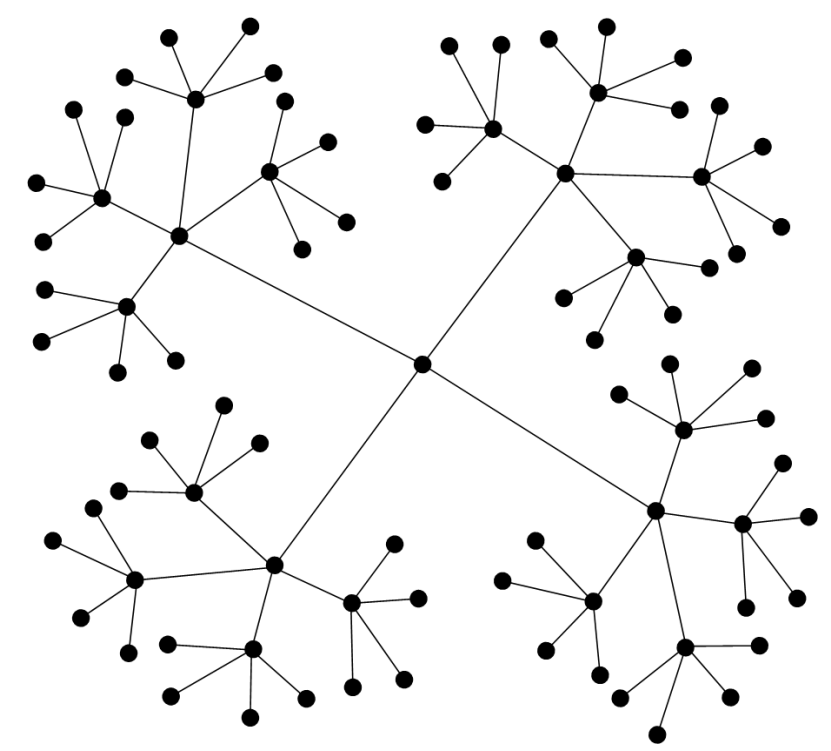

Figure 1. A graph $Q_{3}$

Theorem 1. Let $Q_{d}$ be any quadtree with $d \geq 2$ dimensional. Then

$$
\operatorname{tvs}\left(Q_{d}\right)=2^{2 d-1}+1 \text {. }
$$

Proof. Let $\phi$ be optimal total $k$-labelling with respect to the $\operatorname{tvs}\left(Q_{d}\right)$. To get the smallest $k$ such that the weights of all vertices of $Q_{d}$ are distinct, then the weight of the smallest sequence should start from the pendant vertex up to another vertex. Since the number of pendant vertices of $Q_{d}$ is $4^{d}$ and the weight of any pendant vertex is the sum of two positive integers, the smallest weight among them is at least 2 and the largest weight has value at least $4^{d}+1$. Therefore, $\operatorname{tvs}\left(Q_{d}\right) \geq\left\lceil\left(4^{d}+1\right) / 2\right\rceil=2^{2 d-1}+1$.

Next, we show that $\operatorname{tvs}\left(Q_{d}\right) \leq 2^{2 d-1}+1$. To do this, we construct a total irregular labelling on $Q_{d}$ as follows. All pendant edges are labeled by

$$
1,2,2,3,3,4,4,5, \cdots 2^{2 d-1}, 2^{2 d-1}, 2^{2 d-1}+1 .
$$

The remaining edges are labeled by $2^{2 d-1}+1$. For each vertex of $Q_{d}$, define

$$
s(y)=\sum_{y z \in E} \lambda_{1}(y z)
$$


Write $V:=\left\{y_{1}, y_{2}, y_{3}, \cdots, y_{N}\right\}$ where $N=\sum_{i=0}^{d} 4^{i}$ such that $1=s\left(y_{1}\right) \leq s\left(y_{2}\right) \leq$ $s\left(y_{3}\right) \leq \cdots \leq s\left(y_{N}\right)$. Recursively, define the labelling $\lambda_{1}$ on $V$ and the weight of all vertices as follows:

$$
\lambda_{1}\left(y_{1}\right)=1, w t\left(y_{1}\right)=2
$$

and for $2 \leq i \leq N$

$$
\lambda_{1}\left(y_{i}\right)=\max \left\{1, w t\left(y_{i-1}\right)+1-s\left(y_{i}\right)\right\} \text { and } w t\left(y_{i}\right)=s\left(y_{i}\right)+\lambda_{1}\left(y_{i}\right) .
$$

To find the weights of all vertices, we have two cases.

Case 1. For $\lambda_{1}\left(y_{i}\right)=\max \left\{1, w t\left(y_{i-1}\right)+1-s\left(y_{i}\right)\right\}=1$.

We have,

$$
\begin{aligned}
w t\left(y_{i}\right) & =s\left(y_{i}\right)+\lambda_{1}\left(y_{i}\right) \\
& =s\left(y_{i}\right)+\max \left\{1, w t\left(y_{i-1}\right)+1-s\left(y_{i}\right)\right\} \\
& =s\left(y_{i}\right)+1 \\
& \geq s\left(y_{i}\right)+w t\left(y_{i-1}\right)+1-s\left(y_{i}\right) \\
& >w t\left(y_{i-1}\right) .
\end{aligned}
$$

Case 2. For $\lambda_{1}\left(y_{i}\right)=\max \left\{1, w t\left(y_{i-1}\right)+1-s\left(y_{i}\right)\right\}=w t\left(y_{i-1}\right)+1-s\left(y_{i}\right)$. Then,

$$
\begin{aligned}
w t\left(y_{i}\right) & =s\left(y_{i}\right)+\lambda_{1}\left(y_{i}\right) \\
& =s\left(y_{i}\right)+\max \left\{1, w t\left(y_{i-1}\right)+1-s\left(y_{i}\right)\right\} \\
& =s\left(y_{i}\right)+w t\left(y_{i-1}\right)+1-s\left(y_{i}\right) \\
& >w t\left(y_{i-1}\right) .
\end{aligned}
$$

So that, the weights of all vertices are distinct. By the definition of $\lambda_{1}$, we can show that the maximum label used is $2^{2 d-1}+1$. Therefore, $\operatorname{tvs}\left(Q_{d}\right) \leq 2^{2 d-1}+1$

Next, we present the total vertex irregularity strength of banana tree.

Definition 2. A banana tree, denoted by $B_{n, t}$, is a graph obtained by connecting a vertex $v$ to one leaf of each of $n$ copies of $S_{t}$ ( $v$ is not in any of the stars), where $S_{t}$ is a star graph with $t+1$ vertices.

Figure 2. gives an example of a banana tree with $n=3$ and $t=6$.

Theorem 2. Let $n, k$ be a positive integer number. For $n \geq 3$ and $t \geq 3$,

$$
\operatorname{tvs}\left(B_{n, t}\right)=\left\lceil\frac{n(t-1)+1}{2}\right\rceil .
$$

Proof. Let $\psi$ be optimal total $k$-labelling with respect to the $\operatorname{tvs}\left(B_{n, t}\right)$. To get the smallest $k$ such that the weights of all vertices of $B_{n, t}$ are distinct, then the weight of the smallest sequence should start from the pendant vertex up to another vertex. Since the number of pendant vertices of $B_{n, t}$ is $n(t-1)$ and the weight of 


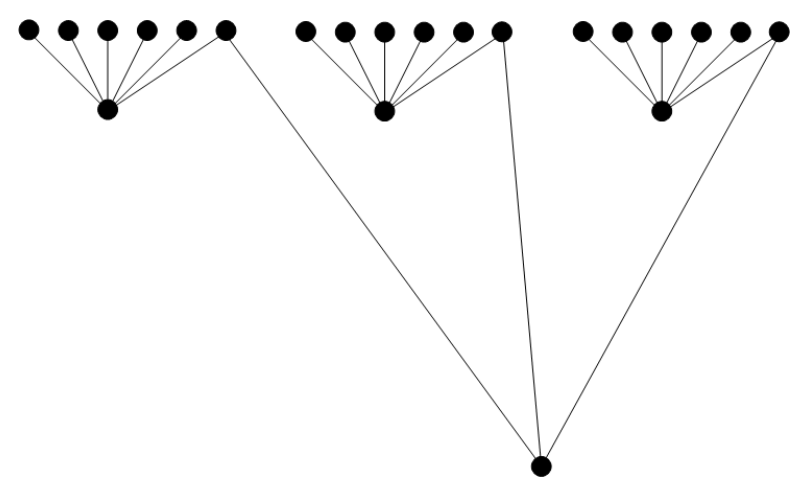

Figure 2. A graph $B_{3,6}$

any pendant vertex is the sum of two positive integers, the smallest weight among them is at least 2 and the largest weight has value at least $n(t-1)+1$. Therefore, $\operatorname{tvs}\left(B_{n, t}\right) \geq\lceil(n(t-1)+1) / 2\rceil$.

Next, we show that $\operatorname{tvs}\left(B_{n, t}\right) \leq\lceil(n(t-1)+1) / 2\rceil$. To do this, we construct a total irregular labelling on $B_{n, t}$ as follows. All pendant edges are labeled by $1,2,2,3,3,4,4,5, \cdots\lceil(n(t-1)+1) / 2\rceil$. The remaining edges are labeled by $\lceil(n(t-$ 1) +1$) / 2\rceil$. For each vertex of $B_{n, t}$, define

$$
s(y)=\sum_{y z \in E} \lambda_{2}(y z) .
$$

Write $V:=\left\{y_{1}, y_{2}, y_{3}, \cdots, y_{N}\right\}$ where $N=n k+1$ such that $1=s\left(y_{1}\right) \leq s\left(y_{2}\right) \leq$ $s\left(y_{3}\right) \leq \cdots \leq s\left(y_{N}\right)$. Recursively, define the labelling $\lambda_{2}$ on $V$ and the weight of all vertices as follows:

$$
\lambda_{2}\left(y_{1}\right)=2-s\left(y_{1}\right), w t\left(y_{1}\right)=2
$$

and for $2 \leq i \leq N$

$$
\lambda_{2}\left(y_{i}\right)=\max \left\{1, w t\left(y_{i-1}\right)+1-s\left(y_{i}\right)\right\} \text { and } w t\left(y_{i}\right)=s\left(y_{i}\right)+\lambda_{2}\left(y_{i}\right) .
$$

To find the weights of all the vertices, we have two cases.

Case 1. For $\lambda_{2}\left(y_{i}\right)=\max \left\{1, w t\left(y_{i-1}\right)+1-s\left(y_{i}\right)\right\}=1$.

We have,

$$
\begin{aligned}
w t\left(y_{i}\right) & =s\left(y_{i}\right)+\lambda_{2}\left(y_{i}\right) \\
& =s\left(y_{i}\right)+\max \left\{1, w t\left(y_{i-1}\right)+1-s\left(y_{i}\right)\right\} \\
& =s\left(y_{i}\right)+1 \\
& \geq s\left(y_{i}\right)+w t\left(y_{i-1}\right)+1-s\left(y_{i}\right) \\
& >w t\left(y_{i-1}\right) .
\end{aligned}
$$


Then,

Case 2. For $\lambda_{2}\left(y_{i}\right)=\max \left\{1, w t\left(y_{i-1}\right)+1-s\left(y_{i}\right)\right\}=w t\left(y_{i-1}\right)+1-s\left(y_{i}\right)$.

$$
\begin{aligned}
w t\left(y_{i}\right) & =s\left(y_{i}\right)+\lambda_{2}\left(y_{i}\right) \\
& =s\left(y_{i}\right)+\max \left\{1, w t\left(y_{i-1}\right)+1-s\left(y_{i}\right)\right\} \\
& =s\left(y_{i}\right)+w t\left(y_{i-1}\right)+1-s\left(y_{i}\right) \\
& >w t\left(y_{i-1}\right) .
\end{aligned}
$$

So that, the weights of all vertices are distinct. By the definition of $\lambda_{2}$, we can show that the maximum label used is $\lceil(n(t-1)+1) / 2\rceil$. Therefore, $\operatorname{tvs}\left(B_{n, t}\right) \leq$ $\lceil(n(t-1)+1) / 2\rceil$

\section{References}

[1] M. BaČA, S. Jendrol', M. Miller, J. Ryan, On irregular total labellings, Discrete Math., 307, 1378-1388, 2007.

[2] Nurdin, E.T. Baskoro, A.N.M. Salman, N.N. Gaos, On total vertex-irregular labellings for several types of trees, Util. Math., 83, 277-290, 2010.

[3] K. Wijaya, Slamin, Surahmat, S. Jendrol', Total vertex irregular labeling of complete bipartite graphs, J. Combin. Math. Combin. Comput., 55, 129-136, 2005. 